\title{
OTIOTOMTCS
}

Revista de economía, empresa y sociedad

ANÁLISIS

\section{F́tica bancaria y banca ética. Dos realidades distintas y posibles}

\section{Joan Ramon Sanchis Palacio}

Catedrático de Organización de Empresas. Universitat de València

RESUMEN El sector financiero, y en particular la banca, es especialmente sensible a la aplicación de la ética empresarial. Por una parte, porque su papel como sector estratégico de la economía es clave y determinante, y por otra, porque durante los últimos años, y en especial desde la crisis financiera del 2008, ha sido protagonista de numerosos casos de escándalos y malas prácticas. La adopción de comportamientos éticos es fundamental en el funcionamiento de los bancos, pues estas organizaciones manejan un activo muy sensible que es propiedad de sus clientes, como es el dinero. Tanto es así, que no solo se habla de la ética bancaria, sino incluso de la existencia de bancos éticos; dos aspectos que son distintos. El presente trabajo tiene por objeto analizar cuáles son las características que definen a la banca ética y qué aspectos son los que la diferencian de la ética bancaria.

PALABRAS CLAVE ética bancaria; banca ética; banca sostenible; responsabilidad social corporativa; bancos

Banking ethics and ethical banking. Two different and possible realities

ABSTRACT The financial sector, and banking in particular, is especially sensitive to the application of business ethics. On the one hand, because its 
role as a strategic sector of the economy is a key and determining factor and, on the other, because during recent years, and especially since the financial crisis of 2008, it has been the protagonist of numerous scandals and bad practices. The adoption of ethical behavior is fundamental in the operation of banks, since these organizations manage a very sensitive asset that is owned by their customers - money. Sota much sota, that not only speaks of banking ethics, but even the existence of ethical banks; two aspects that are different. The purpose of this paper is to analyze the characteristics that define ethical banking and what aspects differentiate it from banking ethics.

KEYWORDS banking ethics; ethical banking; sustainable banking; corporate social responsibility; banks

\section{Introducción}

La ética empresarial se ha convertido en uno de los principales campos de estudio de las organizaciones, tanto desde el punto de vista académico como desde su aplicación al mundo empresarial (Forcadell y Aracil, 2017). Los escándalos protagonizados por algunas empresas (Enron, Parmalat), y las malas praxis que afectan a un número cada vez mayor de consumidores, han sido los causantes del surgimiento de la denominada economía ética, cuyo máximo representante es el premio Nobel de 1998, Amartya Sen.

El sector financiero, y en particular la banca, es especialmente sensible a la aplicación de la ética empresarial. Por una parte, porque su papel como sector estratégico de la economía es clave y determinante (Belás, 2012) y por otra, porque durante los últimos años, y en especial desde la crisis financiera del 2008, ha sido protagonista de numerosos casos de escándalos y malas prácticas (Rosero y otros, 2013). Muchos bancos comerciales, en un ámbito mundial, se han visto involucrados en escándalos públicos sobre problemas éticos ocasionados por comportamientos poco profesionales y escasos de ética como, por ejemplo, el lavado o blanqueo de dinero negro, la malversación de fondos de grandes grupos financieros y su relación con el fraude fiscal a través de paraísos fiscales, la colocación excesiva de créditos y otros productos financieros que provoca quiebras bancarias y problemas con las cuentas y depósitos de los clientes, o las irregularidades en la apertura de cuentas y transferencias de fondos, entre otros (Rosero y otros, 2013; EBF, 2013).

La adopción de comportamientos éticos y el cumplimiento normativo y de códigos éticos es fundamental en el funcionamiento de los bancos, pues estas or- 
ganizaciones manejan un activo muy sensible que es propiedad de sus clientes: el dinero (Bagus y Howden, 2013). Tanto es así, que no solo se habla de la ética bancaria, sino incluso de la existencia de bancos éticos; dos aspectos que son distintos. La Alianza Global por una Banca con Valores (Global Alliance for Banking on Values, GABV), creada en el 2009, está formada por una veintena de bancos líderes en banca ética y sostenible en todo el mundo, y su objetivo es promover una alternativa a un sistema financiero global en crisis (Sasia, 2012). Entre sus miembros se encuentra Triodos Bank, uno de los bancos fundadores y actual presidente de la GABV; el resto de los miembros son entidades de microcréditos, bancos y cooperativas de crédito, dedicados a la financiación responsable. Entre todos, suman activos por encima de los 40.000 millones de dólares, y dan servicio a más de 10 millones de clientes en 20 países de todo el mundo.

A pesar de los múltiples escándalos relacionados con la ética que han afectado a los bancos, y el papel clave que estos desempeñan en el sistema económico, los estudios publicados sobre ética empresarial aplicada a la banca son realmente escasos (Muñoz y otros, 2004; Forcadell y Aracil, 2017). Sin embargo, la necesidad de recuperar parte de la imagen y reputación perdida, sobre todo durante la crisis financiera del 2008, a través de la introducción de prácticas de responsabilidad social empresarial (RSE) y de comportamientos éticos, es evidente (Hur y otros, 2014). En este sentido, existen estudios que han demostrado que la introducción de este tipo de prácticas contribuye de manera positiva a la recuperación de la reputación empresarial y a la obtención de resultados económicos para la organización (Ruiz y otros, 2014).

\section{La ética aplicada a la banca: ética bancaria como necesidad}

El concepto de ética empresarial comienza a desarrollarse a partir de la segunda mitad del siglo xx, y llega a su máximo apogeo a principios del siglo xxi, asociado a otros conceptos también de actualidad como la RSE, el Gobierno corporativo, la sostenibilidad o la ciudadanía corporativa (Zadek, 2000). Su desarrollo como campo de estudio especializado se sitúa en los años setenta del siglo xx (De George, 1995), y surge con un fuerte carácter multidisciplinar, recibiendo aportaciones desde la gestión empresarial, pero también desde otros campos muy diversos, como la teología y la filosofía. Sus primeras aplicaciones se centran en el comportamiento de las grandes corporaciones y en la necesidad de la separación entre la propiedad y la dirección. Durante la década de los ochenta del siglo xx, se extiende con fuerza en el ámbito empresarial y comienzan a surgir instituciones y publicaciones especializadas en esta materia, primero en EE. UU. y posteriormente en Europa. 
La introducción de la ética como un elemento destacado en la toma de decisiones de las organizaciones no se produce solo por la presión social, sino sobre todo porque las empresas han visto en ella una herramienta estratégica para la mejora de sus beneficios económicos, sobre todo a través del marketing. Los comportamientos éticos contribuyen a la mejora de la imagen y de la reputación de las empresas, lo que afecta positivamente a sus ventas e ingresos (de los Ríos y otros, 2012). Como señalan algunos autores, las empresas excelentes convergen hacia la ética (Peters, 2005).

Podemos definir la ética como un conjunto de principios, normas y reglas de conducta que rigen el comportamiento de las personas y los grupos (Carroll, 1991). Su inclusión como pautas de comportamiento empresarial y económico se remonta a los trabajos de los primeros economistas, como Adam Smith o Marshall (Windsor, 2006). Existen diferentes definiciones sobre ética empresarial, aunque la mayor parte ponen el énfasis en la filosofía o el significado moral (Epstein, 1987), y señalan la diferencia entre lo bueno y lo malo (Crane y Matten, 2007).

Fetiniuc y Luchian (2014) definen la ética bancaria como el sistema de reglas y estándares de conducta para las instituciones bancarias y su personal colaborador. De esta definición, se deduce que la ética bancaria abarca dos niveles: la ética corporativa, que comprende los criterios y normas de conducta del banco como institución; y la ética bancaria, que afecta a la conducta de los empleados bancarios. Esta última presenta a su vez una doble dimensión, interna y externa (Romero, 2006). La ética bancaria interna comprende el conjunto de normas y reglas que afectan a las relaciones entre los stakeholders internos del banco (gerentes, propietarios y empleados), y tiene como fin resolver los posibles conflictos internos que se puedan producir entre ellos. Por su parte, la ética bancaria externa afecta a las relaciones de los stakeholders internos con los externos, en especial, la relación de los empleados bancarios con sus clientes, y tiene como finalidad evitar fraudes y malas prácticas (Guzmán y Vera, 2016).

Los principios básicos de la ética bancaria son (Bozovic, 2007): 1) el principio de la confianza mutua entre el banco y sus clientes, a través del cual se establecen los acuerdos contractuales; 2) el principio de interés y beneficio mutuo, según el cual ninguno de los socios en una relación de negocios debe sentirse engañado; 3) el principio de buenas intenciones, que significa que no hay intención de tratar de hacer negocios de forma inmoral, como por ejemplo el fraude, robo o cualquier otra manipulación no deseada; 4) el principio del compromiso empresarial y la tolerancia de negocios se refiere a la armonización de conflictos de intereses entre los participantes en el proceso; 5) el principio de la mejora de la conducta ética de negocios es la disponibilidad del socio para aceptar el error que se cometió como resultado de sus propias acciones; 6) el principio de la desmonopolización de la posición propia, como el comportamiento monopolístico en el mercado, que no 
contiene ningún valor ético; y 7) el principio del conflicto entre los intereses comerciales de los participantes, que se refiere a la incapacidad para relacionarse con los intereses personales comunes, mientras se tienen los mismos valores éticos presentes (Tran, 2014).

Rosero y otros (2013) contemplan tres áreas o componentes diferentes dentro de la ética bancaria: 1) el comercio ético en los mercados financieros (bolsas de valores), cuyo comportamiento depende de las normas por las que se regulan estos mercados y de la posible información asimétrica que pueda existir; 2) las reglas y normas que se establecen para mantener relaciones comerciales con sus clientes, y que tienen que ver con las estrategias comerciales que siguen los bancos para captar y atraer a clientes y para su fidelización; y 3) los dilemas personales de los empleados bancarios que desempeñan sus tareas en las dos áreas anteriores, y cuyo comportamiento está condicionado por los objetivos o retos que la entidad les asigna (Ziemba y Swieszczak, 2013).

\section{La banca ética: una realidad cada vez más patente}

Cuestión distinta es la existencia de la denominada banca ética, también denominada banca social, banca en valores, banca responsable o banca sostenible, que suele utilizarse para definir una banca comprometida con los valores éticos y sociales, frente a la denominada banca convencional (Sasia, 2012; Soler y Melián, 2012; Soler Roig, 2013). Aunque no existe un registro público específico sobre banca ética, ni tampoco tiene una regulación diferente a la banca convencional, posee unas características que definen su comportamiento y que la diferencian del otro tipo de banca. De la Cuesta (2006) señala como elementos diferenciadores: 1) exclusión financiera y racionamiento del crédito: las dificultades para que las pymes puedan acceder a créditos, por ser consideradas como empresas de alto riesgo crediticio, o la exclusión por zonas geográficas o por segmentos en los que el banco no tiene interés en actuar porque la rentabilidad no es suficientemente alta; 2) fomento del sobreendeudamiento: práctica generalizada que promueve un mayor consumo a través de nuevos productos crediticios como las tarjetas de crédito a personas de segmentos vulnerables (jóvenes, personas excluidas, pensionistas, inmigrantes, etc.); y 3) conflicto de intereses y manipulación de los mercados de valores. En este sentido, los principales asuntos que la banca ética está incorporando en su agenda de sostenibilidad giran en torno a cuatro pilares fundamentales (Castro y Romero, 2011): incrementar la inclusión financiera facilitando el acceso al crédito y a los productos/servicios financieros básicos a aquellos colectivos que han quedado excluidos de los circuitos financieros clásicos o habituales; garantizar el acceso de las pymes a la financiación; controlar los impactos derivados de la financiación de 
grandes proyectos en ámbitos como el medioambiente, los derechos humanos, la corrupción, etc.; y fomentar la inversión socialmente responsable como componente fundamental para una adecuada responsabilidad social empresarial.

Los aspectos que caracterizan a la banca ética, según $\mathrm{M}$. de la Cuesta y N. del Río (2001), son: la máxima participación social; la posibilidad de seleccionar el destino de las inversiones no solo bajo el criterio de rentabilidad y riesgos, sino por temas sociales; la gestión eficaz y profesional de la actividad empresarial que supone el nuevo instrumento financiero; la transparencia como valor fundamental, tanto en la gestión administrativa como en la toma de decisiones; la existencia de un código ético (normativas morales y éticas de procesos); y la colocación del activo en proyectos con valor añadido social. Se podrían añadir además otros aspectos relacionados con el comportamiento interno de los bancos éticos, como son la menor diferencia salarial (no superior a la escala 1:10) y la participación de los trabajadores en la toma de decisiones, aunque estos aspectos varían según modelos de banca ética.

De todo lo anterior, se puede definir un banco ético como «la institución que invierte o presta dinero, exclusivamente, con finalidad social o ética, sin renunciar necesariamente a finalidades estrictamente financieras» (San Emeterio y Retolaza, 2003, pág. 136). Así, las principales diferencias entre un banco convencional y un banco ético son las siguientes: el primero busca obtener beneficios económicos, mientras que el segundo busca objetivos tanto económicos como sociales; mientras que el primero prefiere la rentabilidad y la seguridad, el segundo busca el uso ético de su dinero; en el primero, el universo de inversión y financiación es ilimitado y está orientado a las empresas que generan mayor rentabilidad económica, mientras que en el segundo está restringido a las empresas socialmente responsables; la transparencia en el primero es escasa y poco clara, mientras que en el segundo es absoluta; las condiciones crediticias en el primero se sustentan en avales o garantías patrimoniales, mientras que el segundo busca más la viabilidad de los proyectos y su impacto social; en cuanto al diseño de los productos y servicios financieros, el primero los adapta más a las necesidades de la propia entidad, mientras que el segundo los adapta a las necesidades o preferencias de sus clientes; y la toma de decisiones en el primero se basa en directivos y gestores, mientras que en el segundo participan todos los stakeholders, incluidos los trabajadores y los clientes (Castro y Romero, 2011).

La banca ética nace en los años sesenta del siglo xx como una herramienta al servicio de las personas excluidas del sistema financiero, con el fin de proporcionarles financiación para emprender proyectos o negocios de impacto social. Así, los primeros bancos éticos van dirigidos a grupos de personas marginadas o en exclusión social, como las mujeres y las personas de raza negra. Posteriormente, los bancos éticos se van extendiendo, tanto geográfica como socialmente, y a fina- 
les de los sesenta y comienzos de los setenta empiezan a constituirse los primeros bancos éticos en Europa. Hoy día, la banca ética es una realidad contrastada y consolidada y, lo más importante, ha demostrado que la banca puede ser viable manteniendo criterios éticos y sociales. No es necesario especular con el dinero de los clientes para ser rentable desde el punto de vista financiero, y se puede ser rentable desde el punto de vista financiero y social de manera paulatina. Bajo este argumento, cualquier banco podría adoptar criterios éticos en su funcionamiento sin poner en peligro su viabilidad económica, por lo cual conviene señalar que el objetivo debería ser que toda la banca fuera ética, y no tener que diferenciar entre una banca que es ética y otra que no lo es.

Los bancos éticos se basan en los principios de la economía solidaria, que son: 1) igualdad: sistemas de retribución con pocas diferencias salariales; 2) empleo: empleo estable y de calidad y acceso al empleo de los colectivos con mayor riesgo de exclusión; 3) sostenibilidad: protección del medio ambiente y uso adecuado de los recursos naturales; 4) cooperación: colaboración tanto dentro de la organización (entre las personas) como fuera (con otras organizaciones); 5) responsabilidad social: compromiso con el entorno; y 6) ánimo de lucro limitado: reinvertir parte de los beneficios económicos en la sociedad. A través de estos seis principios básicos, los bancos éticos establecen unos códigos de conducta que están basados en dos características principales: la transparencia y la inversión socialmente responsable. Son bancos que utilizan el dinero de los depositantes para invertir en proyectos sociales y medioambientales, y en ningún caso financian actividades fraudulentas, ilegítimas o no éticas, como la fabricación de armamento, el blanqueo de dinero negro, la especulación o el abuso del trabajo. Además, todas sus inversiones son públicas, de manera que cualquier ciudadano puede acceder a esta información y comprobar a qué están destinando su dinero este tipo de bancos (Sanchis, 2016).

\section{Conclusiones}

La ética bancaria representa un campo de estudio de gran interés en la actualidad, por las implicaciones de la crisis financiera del 2008 y por los numerosos y destacados casos de malas prácticas y abusos que se han producido dentro del sector bancario. La necesidad de recuperar la imagen y la reputación perdidas obliga a las entidades del sector bancario y financiero a adoptar nuevas medidas basadas en la ética empresarial. Los bancos éticos son los únicos que mantienen una alta reputación e imagen, por lo que se han convertido en un referente para seguir por parte de la banca convencional. La banca ética correspondería a ejemplos de buenas prácticas dentro del sector bancario. Este tipo de entidades bancarias se 
ha ido extendiendo en un ámbito mundial, en la medida en que han ido surgiendo nuevos casos de malas prácticas. También se ha producido un crecimiento considerable del número de clientes y de operaciones financieras llevadas a cabo en bancos éticos, aunque la cuota de mercado de esta clase de bancos sigue siendo insignificante en comparación con la banca convencional.

Si se quiere extender la ética en el sector bancario, no solo se ha de potenciar la creación y el desarrollo de bancos éticos, sino que además se ha de potenciar la aplicación de los criterios éticos a los bancos convencionales, junto con la transparencia y el buen gobierno corporativo. Solo así se podrá extender la ética al conjunto del sistema bancario. Mientras se hable de bancos éticos, significará que existen bancos que no son éticos, lo que será negativo para los consumidores y para la sociedad en su conjunto. También la sociedad y los ciudadanos han de adquirir conciencia y convertirse en consumidores financieros responsables.

\section{Referencias bibliográficas}

BAGUS, P.; HOWDEN, D. (2013). «Some ethical dilemmas of modern banking». Business Ethics: A European Review (núm. 3, vol. 22, págs. 235-245).

BELÁS, J. (2012). «Social Responsability and Ethics inthe Banking business: Myth or Reality? A case study from TheSlovak Republic». Economic Annals (núm. 195, vol. 57, págs. 115-137).

BOZOVIC, J. (2007). «Business Ethics in Banking». Facta Universitatis Series: Economics and Organization. (núm. 2, vol. 4, págs. 173-182).

CARROLL, A. B. (1991). "The Pyramid of Corporate Social Responsibility: Toward the Moral Management of Organizational Stakeholders». Business Horizons (núm. 34, págs. 39-48).

CASTRO, M.; ROMERO, N. (2011). «Cooperativas de crédito y banca ética ¿un camino por explorar?». CIRIEC-España, Revista de Economía Pública, Social y Cooperativa (núm. 72, págs. 263-300).

CRANE, A.; MATTEN, D. (2007). Business Ethics. Oxford: Oxford University Press.

CUESTA, M. DE LA (2006). «Responsabilidad social del sector bancario. Su contribución a un desarrollo más sostenible». Papeles de Economía Española. (núm. 108, págs. 173-190).

CUESTA, M. DE LA; RÍO, N. DEL (2001). «Dinero más ético y solidario para una sociedad más humana y responsable». Noticias de Economía Pública, Social y Cooperativa (núm. 33, págs. 46-52).

EBF (2013). Corporate Social Responsibility across the Europeanbanking sector: An EBF overview of best practices. Bruselas: European Banking Federation [en línea]. [Consulta: 28 de enero del 2016] <http://www.ebf-fbe.eu> 
EPSTEIN, I. M. (1987). «The Corporate Social Policy Process: Beyond Business Ethics, Corporate Social Responsibility and Corporate Social Responsiveness». California Management Review (núm. 3, vol. 29, págs. 99-114).

FETINIUC, V.; LUCHIAN, I. (2014). "Banking ethics: main conceptions and problems». Annals of TheUniversity of Petrosani Economics (núm. 1, vol. 14, págs. 91-102).

FORCADELL, F. J.; ARACIL, I. (2017). «European banks' reputation for Corporate Social Responsibility». Corporate Social Responsibility and Environmental Management (núm. 1, vol. 24, págs. 1-14).

GEORGE, R. T. de (1995). Business Ethics. Nueva Jersey: Englewood Cliffs.

GUZMÁN, I.; VERA, L. (2016). «La ética como componente esencial en el sector bancario». Revista Empresarial HISSI-FEE-UCSG (núm. 3, vol. 10, págs. 10-17). HUR, W.; KIM, H.; WOO, J. (2014). «How CSR leads to corporate brand equity: Mediating emchanisms of corporate brand credibility and reputation». Journal of Business Ethics (núm. 1, vol. 125, págs. 75-86).

MUÑOZ, M. J.; FERNÁNDEZ, A.; COSTA, M. DE LA (2004). «Responsabilidad social en el sistema bancario: una primera aproximación de evaluación para el caso español». Eben, Papeles de Ética, Economía y Dirección (núm. 12, págs. 1-21).

PETERS, T. J. (2005). Nuevas organizaciones en tiempos de caos. Bilbao: Ediciones Deusto.

RíOS, A. DE LOS; LOZANO, M. R.; VALÈNCIA, P. T.; RUZ, M. C. (2012). «Una aproximación a la relación entre información sobre la responsabilidad social orientada al cliente y la reputación corporativa de las entidades financieras españolas». Cuadernos de Economía y Dirección de la Empresa (núm. 3, vol. 15, págs. 130-140).

ROMERO, G. (2006). «Principios y valores éticos en las organizaciones bancarias respecto a la calidad del servicio y atención al cliente». Revista Venezolana de Gerencia (núm. 36, vol. 11, págs. 638-651).

ROSERO, O. G.; PINZÓN, J. V.; RAMÍREZ, G. A. (2013). «Responsabilidad Social Corporativa en la banca europea: un estudio empírico comparativo entre organizaciones de 15 países». Sotavento (núm. 22, págs. 82-98).

RUIZ, B.; ESTEBAN, A.; GUTIÉRREZ, S. (2014). "Determinants of reputation of leading Spanish financial institutions among their customers in a context of economic crisi». Business Research Quarterly (núm. 4, vol. 17, págs. 259-278).

SANCHIS, J. R. (2016). «La revolución de las finanzas éticas y solidarias». Oikonomics: revista de economía, empresa y sociedad (núm. 6, págs. 28-34).

SANT EMETERIO, J.; RETOLAZA, J. (2003). «¿Existe espacio para una Banca Ética?» LanHarremanak. Revista de Relaciones Laborales (núm. 2, vol. 9, págs. 127-163). 
SASIA, P. (2012). «La Banca ética en Europa: el enfoque del crédito como criterio de configuración de un espacio de alternativa». CIREC-España, Revista de Economía Pública, Social y Cooperativa.(núm. 75, págs. 277-299).

SOLER, C. (2013). «Fiare: un proyecto de banca ética, ciudadana y cooperativa». Revista de Ciencias Humanas y Sociales (núm. 138, vol. 71, págs. 91-111).

SOLER, F. V.; MELIÁN, A. (2012). «Cooperativas de crédito y Banca ética: viejas y nuevas respuestas éticas y solidarias a problemas de siempre». REVESCO. Revista de Estudios Cooperativos (núm. 109, págs. 45-80).

TRAN, I. (2014). "CSR inthe banking sector. A Literature review and newresearch directions». International Journal of Economics, Commerce and Management (núm. 11, vol. 2, págs. 1-22).

WINDSOR, D. (2006). «Corporate Social Responsibility: Three Key approaches». Journal of Management Studies (núm. 1, vol. 43, págs. 93-114).

ZADEK, S. (2000). TheCivil Corporation. TheNew Economy of Corporate Citizenship. Londres: Eartchscan.

ZIEMBA, M.; SWIESZCZAK, K. (2013). «Ethical issues inthe context of banks as public trust organization». Research Papers of the Wroclaw University of Economics (núm. 316, págs. 169-180).

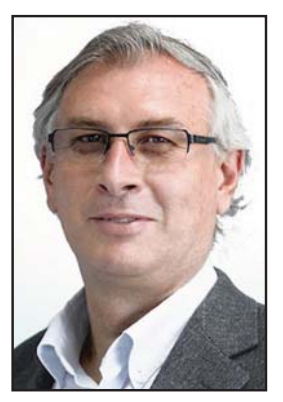

\section{Joan Ramon Sanchis-Palacio joan.r.sanchis@uv.es Catedrático de Organización de Empresas. Universitat de València}

Catedrático de Organización de Empresas de la Universidad de Valencia y doctor en Economía de la Empresa (premio extraordinario de doctorado). Director de la Cátedra de Economía del Bien Común de la Universidad de Valencia. Autor de numerosos artículos científicos sobre economía social, cooperativismo y banca, y de libros como ¿Es posible un mundo sin bancos? La revolución de las finanzas éticas y solidarias, de la editorial EI Viejo Topo, y La banca que necesitamos. De la crisis financiera a la banca ética: una alternativa socialmente responsable, de Publicaciones de la Universidad de Valencia. Coautor de libros como Caixa Popular: un modelo de banca cooperativa social y alternativa y El modelo Consum: una cooperativa responsable y sostenible, editados por Vincle Editorial. 
Los textos publicados en esta revista están sujetas -salvo que se insdique el contrario- a una licencia de Reconocimiento 3.0 España de Creative Commons. Podéis copiarlos, distribuirlos, comunicarlos públicamente y hacer obras derivadas siempre que reconozcáis los créditos de las obras (autoría, nombre de la revista, institución editora) de la manera especificada por los autores o por la revista. La licencia completa se puede consultar en http://creativecommons.org/licenses/by/3.0/es/deed.ca.

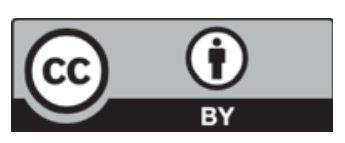

